\title{
ESTRUTURA E AÇÃO NAS ORGANIZAÇÕES: ALGUMAS PERSPECTIVAS SOCIOLÓGICAS
}

\section{RESUMO}

O presente trabalho apresenta uma reflexão teórica sobre a relação objetividade-subjetividade e sua presença no campo de estudos organizacionais, visando a analisar as perspectivas abertas a partir das sínteses teóricas de Giddens e Bourdieu. Expõe algumas contribuições clássicas da teoria organizacional, aprofunda a análise das correntes subjetivistas nos estudos e pesquisas empíricas do campo organizacional, destacando o individualismo metodológico, de forma a considerar a presença significativa dessa corrente nos estudos organizacionais. As contribuições sociológicas de Giddens e Bourdieu são analisadas, sendo que apresentam duas tentativas de síntese no debate objetividade-subjetividade. E, por fim, destaca algumas aplicações dessas perspectivas teóricas no campo de estudo e pesquisa organizacional a partir da visão crítica do pós-modernismo, visando a apontar possíveis perspectivas e limitações.

\section{Alketa Peci \\ EBAPE/FGV}

\begin{abstract}
This paper presents a critical reflection about objectivity-subjectivity relationship and its presence in the organizational studies, aiming an analysis of the theoretical synthesis of Giddens and Bourdieu and its possible impact in organizational theory (OT). The paper presents some classical OT contributions, it deepens the analysis of subjective thought and its status in organizational field, singularizing the importance of methodological individualism and its expressive presence in OT. Giddens and Bourdieu theoretical contributions are examined, considering that they express a synthesis of objectivity-subjectivity debate. At last, some possible applications of this theoretical perspective in OT are accurately studied, based on the critical vision of post-modernism, aiming to identify possible perspectives and limitations of this synthesis to organizational field.
\end{abstract}

PALAVRAS-CHAVE Teoria organizacional, ação, estrutura, teoria organizacional, perspectivas sociológicas KEY WORDS Organizational theory, agency, structure, organization theory, sociological perspectives. 


\section{INTRODUÇÃO}

Os estudos organizacionais caracterizam-se pela dominância da perspectiva objetivista. Prevalecem correntes teóricas, como o contingencialismo e o institucionalismo, que percebem a organização como reflexo das características do ambiente no qual se insere. Assim, o comportamento organizacional consiste em estratégias - adaptativas, reativas, miméticas - que buscam a sobrevivência organizacional, em um contexto de contínua mudança. As organizações, a ação organizacional e a estrutura têm sido vistas como respostas às diversas condições objetivas. Desse modo, os processos sociais e culturais que dão forma à estrutura e ao comportamento organizacional têm sido deixados de lado ou considerados variáveis exógenas, coisificadas como "realidade", "sociedade" ou "ambiente".

As tentativas de introduzir a perspectiva subjetivista nos estudos organizacionais estão mais presentes na área da cultura organizacional ou do processo decisório. No entanto, é possível juntar, sob a denominação "subjetivista", correntes teóricas das mais diversificadas, tais como o cognitivismo, a fenomenologia e o individualismo metodológico, que partem de premissas diferentes.

Este trabalho apresenta uma reflexão teórica sobre a relação objetividade-subjetividade e sua presença no campo de estudos organizacionais, visando a analisar as perspectivas abertas a partir das sínteses teóricas de Giddens e Bourdieu.

A primeira parte apresenta as principais contribuições da teoria clássica organizacional e destaca o papel da subjetividade no campo dos estudos organizacionais. Atenção especial é dedicada ao individualismo metodológico, considerando a enorme presença dessa corrente nos estudos organizacionais, especialmente em relação aos processos decisórios, assim como o importante papel do prêmio Nobel de Economia, Herbert Simon, que contribuiu significativamente para a área organizacional. As contribuições sociológicas de Giddens e Bourdieu são analisadas, sendo que apresentam duas tentativas de síntese no debate objetividade-subjetividade. Por fim, destacam-se algumas aplicações dessas perspectivas teóricas no campo de estudo e pesquisa organizacional e, a partir da visão crítica do pósmodernismo, apontam-se possíveis perspectivas e limitações de tais tentativas de síntese teórica.

\section{TEORIAS ORGANIZACIONAIS: PERSPECTIVAS CLÁSSICAS E $O$ PAPEL DA SUBJETIVIDADE}

\section{Algumas perspectivas consideradas clássicas na TO}

$\mathrm{Na}$ linguagem comum, a palavra organização é usada de duas formas diferentes. Conforme Bonazzi (2000) destaca, por organização é possível denotar um ente social baseado na divisão do trabalho e das competências ou o modo segundo o qual um dado ente social é organizado. Existem organizações bem ou mal organizadas. É objetivo da teoria organizacional compreender as organizações enquanto fenômeno social, mas, também, como toda teoria, o caráter normativo e o prescritivo estão igualmente presentes na idealização ou proposta de modelos que sugerem o melhor modo de se organizar, traduzido em instrumentos "úteis" para a prática organizacional.

Segundo Bonazzi (2000), as contribuições interpretativas da teoria organizacional examinam as dinâmicas sociais observáveis nas organizações. A corrente prescritiva prevalece nas teorias gerenciais e de empresa, enquanto as contribuições interpretativas estão mais presentes na sociologia organizacional. Fazendo uma leitura crítica dessa interpretação de herança positivista, vale lembrar a dificuldade de separar a interpretação da prescrição: a fronteira entre o que a organização é o que a organização deve ser é muito tênue e depende das interpretações e do uso das teorias / ideologias.

Tendo em vista essas observações, apresentam-se algumas perspectivas consideradas clássicas em TO num espaço de tempo limitado, marcado pelo advento da Administração Científica de Taylor. O objetivo é destacar, embora muito brevemente, o que prevalece na teoria organizacional nesse período.

O modelo racional de organização, que encontra suas melhores contribuições em Taylor e Weber, olha a organização como um instrumento para alcançar objetivos predefinidos à base de critérios de racionalidade instrumental. As estruturas legalmente prescritas e a conformidade do comportamento individual a tais estruturas são os objetos principais da análise (Bonazzi, 2000).

Taylor, baseado em uma concepção puritana do trabalho humano, lança suas idéias de administração científica no fim do século XIX, partindo de algumas importantes premissas: natureza maléfica do ser humano, auto-interesse individual, existência de métodos organizacionais inadequados que propiciam o desperdício da energia humana e superioridade da ciência positivista. Para qualquer problema existe sempre o melhor modelo de se organizar, e tal modelo pode ser alcançado por meio da aplicação de métodos científicos de pesquisa. Conseqüentemente, os quatro princípios 
básicos de organização são: estudo científico de métodos de trabalho; seleção e adestramento científico de mão-de-obra; relações de estima e colaboração cordial entre os dirigentes e a mão-de-obra; e, distribuição uniforme do trabalho e das responsabilidades entre a administração e a mão-de-obra.

Weber contribuiu para o estudo da burocracia administrativa enquanto aparelho típico do poder legal. Para Weber, o objeto da Sociologia é estudar a ação dotada de sentido. Os fundamentos, enquanto tipos ideais, de tal ação são: ação racional com respeito ao fim - o sujeito atua racionalmente visando a conseguir um determinado objetivo no mundo externo, avalia os meios em relação aos fins, os fins em relação às conseqüências e, eventualmente, os diversos tipos de fins entre si. As decisões são tomadas com base em cálculos de custos e benefícios. Tal tipo de racionalidade, na opinião do Weber, é uma das características principais do mundo moderno, é a base da ação capitalista, entendida como acumulação metódica, contínua e ilimitada de capital que visa à criação de outro capital; ação racional com respeito ao valor - nesse tipo de ação, o sujeito guia-se pela crença consciente em um determinado valor que se demonstra na ação, independentemente das conseqüências que desta possam derivar; ação baseada nos afetos - determina-se por impulsos, emoções e não por resultados ou valores; ação baseada na tradição - a base de um costume. Muitas das rotinas cotidianas podem ser vistas a partir desse prisma, embora a ação afetiva também possa estar presente.

Com base no tipo ideal - um procedimento de abstração, conceito qualitativo construído por meio de seleções e acentuações unilaterais, que serve para comparar fenômenos -, Weber examina a burocracia. Esse tipo ideal é concebido como um aparelho ótimo dotado de racionalidade com relação aos fins.

Depois de Weber, um pressuposto predominou no estudo das organizações: a burocracia como a única forma das organizações racionais. Vários estudiosos, como Merton e Gouldner, aplicaram a abordagem funcionalista aos termos weberianos da burocracia e confrontaram a intenção racional, com a qual os sujeitos agem, com as consequências não esperadas que derivam no nível da estrutura. Mas, somente a partir dos anos 1960, a pesquisa organizacional começou a questionar esse pressuposto weberiano e reconhecer que outras formas organizacionais mais flexíveis podem existir ao lado das burocracias.

Outros autores questionaram os fins da organização. Por exemplo, Drucker, em sua gestão por objetivos, argumenta que a busca do lucro máximo não é - e não deve ser - o único objetivo da organização. Um conjunto de objetivos concreto e variável no tempo dirige uma busca limitada de lucros, de modo a compensar os riscos da atividade econômica. Esse conjunto de objetivos substitui a importância das normas impessoais da burocracia weberiana. Na visão de Drucker, as capacidades estratégicas de indivíduos - especialmente gerentes - ganham mais importância. Mas, como se observa, o caráter instrumental da racionalidade da organização predomina.

$\mathrm{Na}$ segunda vertente de modelos organizacionais encaixa-se o modelo natural (denotação de Gouldner), que olha a organização como um sistema composto de partes organicamente interdependentes. A realização de propósitos predefinidos perde a relevância e as mudanças não são dadas conforme princípios da racionalidade instrumental, mas como respostas $\mathrm{cu}$ mulativas que visam à sobrevivência do sistema organizacional, adaptando-se ao ambiente. A escola de relações humanas, a teoria da contingência, assim como a visão sistêmica de Parsons, são mais próximas dessa corrente.

\section{Subjetividade nos estudos organizacionais}

Deixando de lado o individualismo metodológico de Simon, perspectivas teóricas baseadas no reconhecimento da subjetividade - como fenomenologia e existencialismo - sempre tiveram pouco espaço nos estudos organizacionais. Nos anos 1970, os paradigmas existentes como teoria de sistemas e de contingência enfatizavam a importância de fatores - à primeira vista objetivos - como ambiente e tecnologia, e buscavam conexões estruturais, além das escolhas e estratégias humanas. Expressões, de uso corrente até os dias de hoje, como "a empresa atua de tal forma", "pensa dessa maneira" ou "reage assim", simbolizam o grau de reificação do objeto "organização".

O fato de as estruturas organizacionais serem similares em diferentes países do mundo influenciou, por longos períodos, a objetividade presente nos estudos organizacionais. Foi no âmbito dos estudos culturais que tal perspectiva começou a ser questionada e a dimensão mais qualitativa das organizações colocou-se em evidência.

Os anos 1970 marcam a maturação do debate subjetividade-objetividade, ação-estrutura, significadofunção na pesquisa organizacional. Partindo das premissas objetivistas do funcionalismo de Parsons, passando pela contribuição de Simon e sua resistência a 
não reificar seu objeto de estudo, e voltando à reificação com a abordagem contingencial, o paradigma vigente entra em crise. O encontro com a antropologia cultural e a sociologia urbana fez com que a pesquisa etnográfica começasse a ser utilizada cada vez mais como instrumento de pesquisa organizacional (Bonazzi, 2000). Ver figura 1. ca dos mecanismos causais que servem como unidade básica das Ciências Sociais, baseado, principalmente, na teoria da escolha racional. Segundo o autor, a unidade elementar da vida social é a ação humana individual. Explicar as instituições e a mudança social é mostrar como elas instituem-se como resultado da ação e interação de indivíduos. Tal perspectiva, conhecida

Figura 1 - Algumas perspectivas sociológicas

\begin{tabular}{|l|c|c|}
\hline & Abordagem Objetivista & Abordagem Subjetivista \\
\hline Recursos simbólicos & Culturalismo, funcionalismo normativo & Cognitivismo, fenomenologia \\
\hline Recursos materiais & Estruturalismo, marxismo & Individualismo metodológico \\
\hline
\end{tabular}

Fonte: Bonazzi (2000).

Marcada pela influência de um número de escolas fenomenologia, simbolismo, cognitivismo, etnografia etc. -, a teoria organizacional retoma o aspecto subjetivo nos estudos organizacionais.

Karl Weick contribui com a corrente subjetivista de estudos organizacionais partindo do ponto de vista de que o mundo externo não tem um sentido em si, são os seres humanos que atribuem sentido ao mundo. Nesse sentido, o processo cognitivo por meio dos quais os indivíduos dão sentido aos fluxos de experiência devem ser objeto de estudo. Um de seus conceitos mais utilizados nos estudos organizacionais relaciona-se com os mapas cognitivos, ou causais, construções dotadas de sentido e ordem lógica. Talvez seja esta uma das principais diferenças entre o cognitivismo e a fenomenologia, segundo a qual não devem existir premissas na análise do objeto, e é ele que vai nos mostrar, por meio da variação, as múltiplas e inesgotáveis facetas de sua compreensão, tentando compreender os pressupostos de sua existência, aquilo que é considerado como natural e nunca é questionado.

Tendo em vista o espaço limitado deste trabalho, enfocar-se-á o individualismo metodológico, considerando a contribuição notável dessa corrente no campo de estudos organizacionais. A parte a seguir baseia-se no suporte teórico de Elster (1989), filósofo e cientista social, importante representante dessa corrente de estudos.

Individualismo metodológico e seu importante papel na T0

Elster (1989) apresenta algumas considerações acer- como individualismo metodológico ${ }^{1}$, serve como base para várias teorias no campo organizacional.

Em nível individual, explicar uma ação é olhá-la como resultado final de dois filtros. O indivíduo encontra-se frente a uma ampla gama de ações possíveis. O primeiro filtro compõe-se de todas as limitações físicas, econômicas, legais e psicológicas que o indivíduo enfrenta. O segundo filtro determina quais ações, dentro do conjunto de oportunidades, serão, de fato, desempenhadas. Os principais mecanismos considerados são: escolha racional e normas sociais.

Para o autor, os mecanismos geradores de escolha são mais fundamentais do que os mecanismos geradores de normas. Na perspectiva da escolha, as ações são explicadas por oportunidades e desejos: o que as pessoas podem fazer e o que elas querem fazer. Às vezes, as limitações são tão fortes, que pouco espaço é deixado para o segundo filtro (escolha ou norma) operar. O conjunto de oportunidades é reduzido a uma única possibilidade de ação.

O debate sobre a relativa importância de oportunidades ou preferências é controverso. No entanto, o autor aponta que, pelo menos em um aspecto, as oportunidades são mais básicas que os desejos: são mais fáceis de serem observadas, não apenas pelos cientistas sociais, mas também por outros indivíduos na sociedade. Outra razão tem a ver com a possibilidade de influenciar o comportamento. É mais fácil - no sentido custo-benefício - mudar as circunstâncias e oportunidades humanas do que mudar os modos de pensar. As oportunidades são externas ao indivíduo, ob- 
jetivas. Desejos são internos e subjetivos. A dificuldade reside em como os elementos objetivos e subjetivos interagem para produzir uma ação.

Com base nessas considerações, apresenta-se a teoria da escolha racional, segundo a qual, quando as pessoas enfrentam diversos cursos de ação, elas geralmente farão o que acreditam irá alcançar o melhor resultado geral.

Escolha racional é instrumental: é dirigida pelos resultados das ações, por isso é tão influente na teoria organizacional. A escolha racional tem relação com o encontro dos melhores meios para dados fins. No entanto, as pessoas escolhem o que elas acreditam ser o melhor meio. $O$ processo pode ser racional, mas não verdadeiro. A verdade é uma relação entre a crença e o objeto da crença. A racionalidade é uma relação entre a crença e no que essa crença se baseia.

Elster apresenta uma análise interessante sobre a ação humana e oferece contribuições pertinentes sobre a interação. Ele considera que muitos eventos apresentam conseqüências não-intencionais - objeto das Ciências Sociais - devido à interação e interferência social.

Segundo o autor, a ação coletiva define-se com base na cooperação: "Cooperar é atuar contra o próprio interesse de modo a que todos possam se beneficiar, caso alguns, ou possivelmente todos, atuem da mesma maneira" (Elster, 1989, p. 126). Problemas da ação coletiva tornam-se evidentes porque é difícil fazer com que as pessoas cooperem para seu benefício mútuo. Resolver o problema é alcançar cooperação mutuamente benéfica.

Parece óbvio que a existência das organizações devese principalmente à superação de tais dilemas. Taylor foi um dos primeiros a reconhecer que a organização é um corretivo das limitações humanas, mas baseia-se em uma concepção perversa da natureza humana.

A relação entre as limitações humanas e a necessidade de recorrer à cooperação organizada é enfatizada por Barnard (1971) em seu livro As funções do executivo, publicado originalmente em 1938. Barnard é um dos primeiros a ser influenciado pelo progressivo declínio do individualismo utilitarista (darwinismo social), a favor de uma filosofia que considera a sociedade como uma entidade cooperativa regulada por princípios morais. O autor define as organizações como sistemas cooperativos: complexos de componentes físicos, biológicos, pessoais e sociais, que estão em uma relação sistêmica específica, em virtude da cooperação de duas ou mais pessoas visando a um alvo definido. A ação cooperativa de membros - sejam eles funcionários, gerentes ou proprietários - está na base da análise de Barnard. Escrito no auge do sucesso da administração científica de Taylor, o autor, um prático e agudo observador do fenômeno organizacional, introduziu vários conceitos relacionados com a psicologia e a sociologia das organizações, fortemente influenciado por Mary Parker Follet e Fayol.

$O$ autor considera o indivíduo como "coisa total, singular, única, independente, isolada, abarcando inúmeras forças e matérias passadas e presentes, que constituem fatores físicos, biológicos e sociais" (Barnard, 1971, p. 44). Ele parte da premissa de que o poder de escolha é limitado. O livre-arbítrio também é limitado porque o poder de escolha dos seres humanos é paralisado se for grande o número de oportunidades iguais. A limitação das possibilidades é necessária para a escolha. "A tentativa de limitar as condições de escolha, de forma que torne praticável o exercício de querer, é o que chamamos de criar ou realizar um 'propósito', ou finalidade" (Barnard, 1971, p. 45). Os objetivos são vistos como tentativas de limitar as condições de escolha. As limitações, dentro das quais a escolha é possível, são impostas pela presença conjunta de fatores físicos, biológicos e sociais. Em coerência com o arcabouço teórico oferecido por Elster (1989), o autor enfatiza que as escolhas são feitas com base em propósitos, desejos, impulsos do momento e alternativas externas ao indivíduo, por ele reconhecidas como aproveitáveis ou úteis - ou seja, oportunidades.

Eis algumas idéias do autor: "A implicação mais comum da filosofia do individualismo, da escolha ou livre-arbítrio, reside na palavra 'propósito'. A expressão mais comum da filosofia, oposta da determinação, do behaviorismo, do socialismo, é 'limitação'. Da existência de propósitos de indivíduos - ou da crença em sua existência - e da experiência de limitações, origina-se a cooperação para atingir propósitos e superar limitações" (Barnard, 1971, p. 52).

"Cooperação e organização, como são observadas e experimentadas, são sínteses concretas de fatos opostos, bem como de pensamentos opostos e emoções dos seres humanos. A função do executivo é exatamente a de facilitar a síntese de forças contraditórias em ação concreta, para reconciliar forças, instintos, interesses, condições, posições e idéias conflitantes" (Barnard, 1971, p. 51).

Retomando a análise de Elster, e em coerência com o pensamento de Barnard, seria um erro supor que a motivação central da cooperação seria o interesse pró- 
prio do indivíduo. Existe um conjunto de fatores entre os quais sempre estão presentes motivações nãoegoísticas.

$\mathrm{Na}$ corrente de estudos organizacionais, o autor que mais se destaca na aplicação da perspectiva da escolha racional é Simon. O objetivo de sua análise não são os fins e as funções desempenhadas pelas organizações, mas os comportamentos humanos concretos nas organizações. Nas organizações, as pessoas são vistas como sujeitos que tomam decisões continuamente. Assim, a decisão torna-se o objeto principal do conhecimento administrativo.

Simon revoluciona - ganha o Nobel em Economia e "adota-se" como teórico da área organizacional - quando enfatiza o caráter limitado da racionalidade humana. As limitações objetivas do conhecimento, a impossibilidade de prever todas as conseqüências, a incapacidade de considerar, simultaneamente, numerosas variáveis na tomada da decisão, a incerteza interna a qualquer hierarquia de preferências, a disposição mental e as convicções devidas à cultura e a outros condicionamentos sociais fazem com que, na maioria dos casos, as decisões sejam tomadas com base no critério da satisfação, em vez de otimização.

A análise de Elster coincide com a de Simon quando os dois reconhecem que as ações podem influenciar decisões ou, como Elster aponta, as ações influenciam desejos e oportunidades. Isso torna o processo de análise extremamente complexo e influencia na limitação da racionalidade.

Simon retoma o modelo proposto por Barnard em 1938. As organizações oferecem o modo mais eficaz de integrar e coordenar o comportamento humano, mantendo a racionalidade em nível alto. O equilíbrio entre os incentivos e as contribuições, proposto por Barnard como princípio geral do funcionamento de uma organização, é retomado na análise de Simon. Esse equilíbrio é visto como o resultado do fluxo de decisões racionalmente limitadas - tomadas pelos indivíduos no âmbito das organizações. Assim, o sujeito confronta as contribuições que é disposto a dar com os incentivos materiais ou morais - que espera receber.

Diferentemente dos funcionalistas, Simon não analisa apenas o consenso dos membros de uma organização, mas também as causas e as formas dos conflitos que possam ser de natureza individual ou organizacional.

Atuar racionalmente é fazer bem, enquanto puder, para si mesmo. "A noção da racionalidade é definida para um indivíduo, não para uma coletividade de dois ou mais indivíduos" (Elster, 1989, p. 29). No entanto, quando duas ou mais pessoas interagem, as consequêencias da interação podem ser diferentes das esperadas. Estudar a organização é estudar os efeitos da interação entre indivíduos. A análise de Simon olha a organização como resultado das ações - coordenadas e racionalmente limitadas - de um conjunto de pessoas que agem baseadas em premissas internas e externas à própria organização. Assim como Elster (1989), que é cético em relação à modelagem organizacional, para Simon, as decisões individuais são vistas como um processo no qual determinados meios são escolhidos visando a alcançar determinados fins. Baseado no positivismo lógico, Simon considera a adequação de meios como objeto de juízos de fato e a escolha dos fins como objeto de juízos de valor. Embora tal definição lembre Weber, Simon não reconhece a tensão criada entre esses juízos, mas os coloca em uma contínua relação.

Outros autores contribuíram na mesma linha de estudos que enfatiza o processo decisório nas organizações. Na administração pública, o processo decisório incremental apresenta-se, para Linbdlom, como a melhor forma de fazer políticas públicas. O autor observa que grande parte das decisões políticas é tomada com base em um processo decisório incremental. "Rupturas" associam-se com grandes riscos políticos, que poucos governantes são capazes de enfrentar. Por meio de um processo decisório incremental - muddling through -, assegura-se maior flexibilidade e adaptabilidade às condições incertas do ambiente.

\section{SUBJETIVIDADE-OBJETIVIDADE: A PERSPECTIVA ABERTA COM OS ESTUDOS SOCIOLÓGICOS}

As contribuições de Giddens e Bourdieu na Sociologia têm em comum a tentativa de apresentar uma síntese das perspectivas que enfatizam a objetividade e a subjetividade, representando, para o campo da Sociologia, o esforço de superação da crise do funcionalismo parsoniano e do determinismo estrutural marxista.

Aqui reside a principal semelhança das propostas teóricas dos dois autores: a superação de dicotomias como ação-estrutura, objetividade-subjetividade e indivíduo / pessoa-sociedade. Ainda, os dois autores concebem seus referenciais teóricos a partir de uma relação dialética entre essas dicotomias.

Como se pode perceber no decorrer do texto, eles constroem seus - substancialmente diferentes - 
referenciais teóricos influenciados por diversas perspectivas, aprofundando e reelaborando conceitos da fenomenologia - conceito de habitus em Bourdieu ou conhecimento tácito e reflexividade em Giddens; do individualismo metodológico - mais presente em Giddens, mas também adaptado nas definições de jogo / interesse de Bourdieu; do estruturalismo - mais presente em Bourdieu, por exemplo, na definição do habitus como estruturas estruturantes, mas também forte em Giddens, em seu conceito de estrutura; e, ainda, do funcionalismo e do pragmatismo - Giddens -, assim como do marxismo - Bourdieu.

\section{Anthony Giddens}

A principal contribuição de Giddens na área da Sociologia relaciona-se à sua teoria de estruturação que, a partir de uma visão dinâmica, visa a permitir o estudo da ação de atores individuais e os impactos da estrutura sobre eles, facilitando ou dificultando essa ação e possibilitando mudanças na ação dos indivíduos, assim como mudanças na sociedade.

Como o autor reconhece, a teoria de estruturação visa a preencher um vácuo: a falta de uma teoria de ação nas Ciências Sociais. Relendo as contribuições estruturalistas - em especial de Saussure e Levy-Strauss - e funcionalistas ${ }^{2}$ em relação aos conceitos de estrutura e sistema, o autor propõe uma teoria de agência que tem por objetivo captar as relações espaciais inerentes à constituição de todas as interações sociais. $\mathrm{O}$ autor busca relacionar a ação humana com a explicação estrutural. Ele argumenta que as noções de ação e estrutura pressupõem uma a outra, mas o reconhecimento dessa relação dialética requer a reelaboração dos conceitos relacionados com cada um dos termos (Giddens, 1979, p. 53).

A teoria de estruturação enfatiza que a compreensão dos sistemas sociais situados no tempo-espaço possa ser efetuada vendo a estrutura não no tempo e no espaço, mas como ordem virtual de diferenças, produzida e reproduzida em interações sociais, como meio e produto (Giddens, 1979, p. 3).

Giddens (1979, p. 69) visa à superação de dualismos: tipos voluntarísticos versus tipos determinísticos, sujeito-objeto, indivíduo-sociedade, estática-dinâmica e outros. A teoria de estruturações envolve o conceito de dualidade da estrutura, que tem a ver com a recursividade essencial da vida social e expressa a dependência mútua de estrutura e agência, tal como se apresenta nas práticas sociais. A estrutura é meio e produto da reprodução das práticas (Giddens, 1979, p. 5).
O ator social, visto como agente, conhece boa parte das condições da reprodução da sociedade a que ele pertence - perspectiva negada no estruturalismo e no funcionalismo. A partir da consciência e da agência humana, Giddens diferencia os conceitos de consciência prática - conjunto de conhecimentos tácitos utilizados em práticas sociais, presente no nível do subconsciente e referente à intencionalidade, mas não se revelando por meio de práticas discursivas - e consciência discursiva - referente ao conhecimento que os atores podem expressar por meio de discursos (Giddens, 1979 , p. 25). Baseado em Wittgenstein, Giddens (1979, p. 34) escreve que "o que não pode ser dito é (...) o que deve ser feito: os significados dos itens lingüísticos são intrinsecamente envolvidos com as práticas que abrangem as formas de vida", diferenciando-se do estruturalismo, para o qual o tácito é identificado com o inconsciente.

As atividades sociais humanas são recursivas, ou seja, elas não são criadas pelos atores sociais, mas são continuamente recriadas por eles. Envolvidos em tais atividades e por meio destas, os agentes reproduzem as condições que tornam as atividades sociais possíveis. No entanto, a ordem recursiva das práticas sociais torna-se possível por causa da forma reflexiva de conhecimento dos agentes humanos. A continuidade das práticas presume reflexividade, mas esta última torna-se possível como conseqüência da continuidade das práticas sociais, que se tornam distintivamente "as mesmas" no espaço e no tempo (Cassell, 1993, p. 89-90).

Assim, a intencionalidade do sujeito - crucial para a fenomenologia - elabora-se com base no conceito de monitoramento reflexivo da conduta apresentado por Kristeva, de modo a abranger o conceito de consciência prática. Tal concepção considera as razões e intenções iniciadas rotineira e cronicamente na atividade social humana. O caráter intencional das ações humanas deve ser visto como um fluxo contínuo e não como um conjunto de estados de consciência que, de alguma forma, acompanham a ação (Giddens, 1979, p. 3940).

O modelo estratificado do ser atuante envolve, ao lado do monitoramento reflexivo, a racionalização e a motivação da ação como conjuntos relacionados de processos. Assim, a síntese de Giddens resume-se na Figura 2.

Outro conceito de Giddens, menos utilizado no campo de estudos organizacionais, tem a ver com a conceituação das relações de poder, enquanto relações regularizadas de autonomia e dependência. Baseado no 
reconhecimento da agência, Giddens enfatiza que, por mais subordinado que o ator possa ser em uma relação social, o fato de estar envolvido em tal relação lhe dá um certo poder sobre o outro, fazendo uso dos recursos que ele possui. A partir da dualidade da estrutura, ele olha o poder simultaneamente como capacidade transformadora - enfatizada pela filosofia da ação - e como dominação - propriedade estrutural.

$O$ autor ressalta a importância do ciclo que se estabelece entre as consequêencias não intencionais ${ }^{3}$ da ação dos atores - objeto da análise funcionalista e estrutural - e as intenções da ação humana - enfatizadas na filosofia da ação. "A fuga da história das intenções humanas e o retorno das consequências dessa fuga como influências causais na ação humana são características cruciais da vida social" - realça o autor (Giddens, 1979, p. 7), em coerência com Elster.

\section{Pierre Bourdieu}

A síntese de Bourdieu baseia-se em dois conceitos principais: habitus e campo. Assim como Giddens, Bourdieu oferece uma síntese das perspectivas subjetivista e objetivista, mas caracteriza-se por uma propensão estruturalista mais forte e mantém vários conceitos marxistas em sua análise.

Um filósofo de formação, mas convertido às Ciências Sociais, Bourdieu é influenciado pela tradição fenomenológica-existencialista que dominou o pensamento francês nos anos 1950, assim como pela nova corrente estruturalista. Seus trabalhos de campo e o acesso à area teórica da antropologia estrutural permitem-lhe reconstruir o conceito de habitus ${ }^{4}$, que visa a explicar "as relações de afinidade entre as práticas dos agentes e as estruturas objetivas" (Pinto, 2000, p. 38).

Bourdieu (1972, p. 188) considera habitus como "um sistema subjetivo, mas não individual, de estruturas interiorizadas, esquemas de percepção, de concepção e de ação que são comuns a todos os membros do mesmo grupo ou da mesma classe". "Habitus, uma relação objetiva entre duas objetividades, torna possível uma ligação inteligível e necessária a ser estabelecida entre as práticas e a situação, o significado que é produzido pelo habitus por meio das categorias de percepção e apreciação que são, em si, produtos de uma condição social observável" (Bourdieu, 1984, p. 101).

Ou seja, o habitus é o conceito-chave para a síntese subjetividade-objetividade de Bourdieu, uma vez que deve ser compreendido como uma gramática gerativa de práticas conforme as estruturas objetivas de que ele é produto. O habitus não só interioriza o exterior, mas também exterioriza o interior (Pinto, 2000). Tais estruturas interiorizadas, incorporadas pelos agentes sob a forma de um senso prático que facilita a orientação nos domínios concernentes das existências sociais, apresentam quatro dimensões principais: disposicional $^{5}$, distribucional ${ }^{6}$, econômica ${ }^{7}$ e categóri$\mathrm{ca}^{8}$, que se fazem presentes de forma associada no trabalho empírico (Pinto, 2000, p. 39-41).

Analisando os estilos de vida, Bourdieu (1984, p. 170) conceitua habitus como princípio gerador de julgamentos objetivamente classificáveis e, paralelamente, como sistema de classificação de tais práticas. As condições de existência objetivamente classificáveis e a posição na estrutura das condições de existência geram o habitus: estrutura estruturante, que organiza práticas e percepções das práticas, mas também estrutura estruturada, considerando que o princípio de divisão em classes lógicas, o qual organiza a percepção do mundo social, é, em si, produto da internalização da divisão social em classes.

Por meio de pesquisas empíricas, Bourdieu conclui que a aquisição do habitus não é um processo de aprendizagem mecânica9. Todas as sociedades prevêem formas de transmissão de práticas, que, embora espontâneas, apresentam exercícios estruturais tais como encontrados na pesquisa empírica sobre a sociedade kabila: a observação silenciosa das reuniões de homens, a participação cotidiana na troca de presentes, comunicações léxicas e gramáticas, relações mãe-pai etc.

Estudando a condição de classe e o condicionamento social, o autor alerta que indivíduos agrupados em classes trazem com eles, além das propriedades pertinentes com base nas quais se classificam, outras secundárias, às vezes ocultadas nos modelos aleatórios. A classe social não é definida por uma propriedade, por uma coleção de propriedades, ou por uma cadeia de propriedades que partem de uma propriedade central em uma relação causa-efeito, condicionante-condicionado, mas pela estrutura das relações entre todas as propriedades pertinentes - estrutura esta que dá seu valor específico a cada uma das propriedades e aos efeitos que elas exercem nas práticas (Bourdier, 1984, p. 104).

Quebrando com o pensamento linear, Bourdieu aconselha à reconstrução de redes de relações interligadas que são presentes em cada um dos fatores. Paralelamente, ele reconhece que, de um lado, os agentes não são completamente definidos pelas propriedades que possuem em um dado momento, cujas condições de aquisição persistem no habitus. De outro lado, a re- 
lação entre a posição social inicial e a atual é estatística e de uma intensidade muito variável (Bourdieu, 1984). Ao aproximar o possível e o provável, a esperança subjetiva e a probabilidade objetiva, mediante a noção de habitus, ele modifica a perspectiva fenomenológica-existencial (Pinto, 2000).

A ambição teórica de superação da alternativa entre o subjetivismo - a fenomenologia - e o objetivismo o estruturalismo - encontra um de seus meios privilegiados de realização no binômio habitus-campo (Pinto, 2000, p. 70). Por campo Bourdieu entende espaços estruturados de posições que podem ser analisadas independentemente das características de seus ocupantes. Existem leis gerais dos campos, embora estes possam ser tão diferentes entre si como o campo da filosofia, da política, da religião etc. Toda vez que se analisa um novo campo, serão descobertas propriedades específicas, mas, ao mesmo tempo, serão reconhecidos mecanismos universais. Todo campo pode ser definido em função de jogos e interesses específicos e próprios, irreduzíveis aos jogos e interesses de outros campos. A estrutura do campo é um estado de relação de forças entre agentes ou instituições engajadas na luta, ou, se preferível, na distribuição do capital específico, o qual, acumulado no curso das lutas anteriores, orienta as estratégias ulteriores (Bourdieu, 1984b).

Mas Bourdieu (1984, p. 119-20), criticando a visão utilitarista nas Ciências Sociais, insiste em que o princípio das estratégias presentes nos campos - filosóficos, literários e outros - não é o cálculo cínico, a busca consciente da maximização do ganho, mas uma relação inconsciente entre um habitus e um campo. O habitus, sistema de disposições adquiridas por meio da aprendizagem implícita ou explícita, funciona como um sistema de esquemas gerador de estratégias que possam ser objetivamente conformadas aos interesses objetivos de seus atores.

A perspectiva teórica de Bourdieu caracteriza-se por um considerável grau de determinismo, expresso, talvez com maior força, na busca de homologias entre diferentes campos. O autor não nega a ambição de construir uma teoria unificadora. Os esquemas geradores do habitus são aplicados, por meio de transferência, à maioria das áreas de práticas. As estruturas de oposição nas diferentes áreas de práticas são homólogas entre si, uma vez que são homólogas à estrutura de oposições objetivas entre condições de classes (Bourdieu, 1984, p. 177).

Com uma linguagem próxima à da física, o autor destaca: "os indivíduos não se movimentam no espaço social de uma maneira randômica, isto devido em parte ao fato de que eles se sujeitam a forças que estruturam esse espaço social e, em parte, porque eles resistem às forças do campo com sua inércia específi-

Figura 2 - Modelo estratificado de ação

Condições de ação não reconhecidas

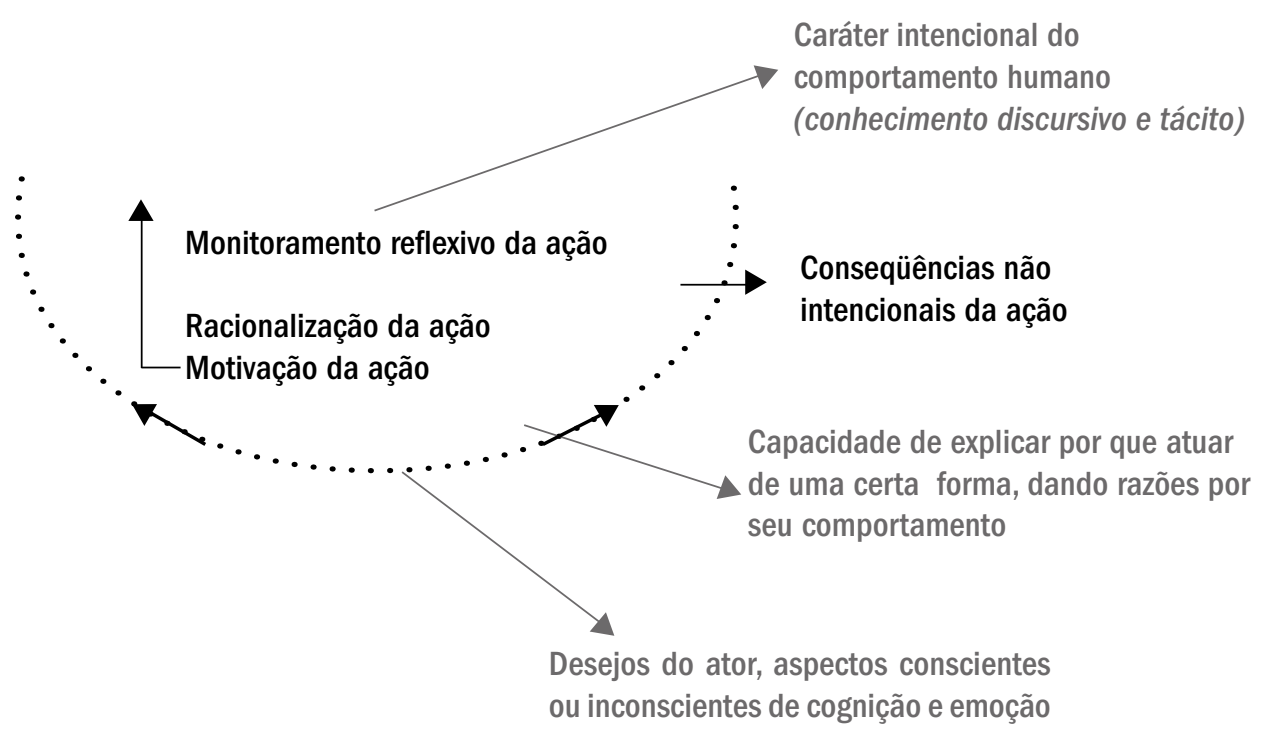

Fonte: Giddens (1979 p. 56). 
ca, isto é, suas propriedades, que podem existir em formas corporificadas, como disposições, ou em formas objetivadas, como bens, qualificações etc." (Bourdieu, 1984(b), p. 109).

\section{QUAIS AS CONTRIBUIÇÕES DAS SÍNTESES OBJETIVIDADE-SUBJETIVIDADE PARA A TEORIA ORGANIZACIONAL?}

Para analisar as contribuições desses autores na teoria organizacional, é importante levar em consideração a passagem e o impacto dos pós-modernos no campo dos estudos organizacionais. Conforme Calás e Smircich (1999) destacam, o pós-modernismo tem sido usado para identificar várias perspectivas que têm em comum algumas características, tais como preocupação com a linguagem e a representação e uma reconsideração da subjetividade e do poder. Embora ainda insuficientemente explorados, alguns dos argumentos dessa perspectiva, como a incredibilidade nas metanarrativas, a crise da representação e a problematização do sujeito e do autor, têm tido particular influência nos estudos organizacionais.

Pós-modernismo ${ }^{10}$ é estruturalismo revisado; revisado como conseqüência do impacto da fenomenologia de Husserl na formação dos novos estruturalistas franceses, como Foucault e Derrida - e Bourdieu. "A fenomenologia prometia sobretudo pôr fim à ignorância filosófica no que concernia às Ciências Humanas, mas procurando evitar a armadilha do positivismo" (Pinto, 2000, p. 23).

Calás e Smircich (1999) destacam que a exaustão do estruturalismo se refere principalmente às expectativas frustradas da teoria social francesa em relação a esse paradigma derivado da linguística estruturalista ou estruturalismo: oferecer um status científico às $\mathrm{Ci}$ ências Humanas. Essa vertente, baseada na semiologia de Saussure, olha a linguagem como um sistema estrutural de relações e diferenças. Desde a Antropologia Levy-Strauss -, à Literatura - Barthes - e à Filosofia Althusser -, o estruturalismo ofereceu uma resposta particular ao excessivo subjetivismo e intencionalidade da fenomenologia e do existencialismo, assim como ao excessivo determinismo social e econômico do marxismo convencional.

O novo estruturalismo nega a noção de subjetividade trazida pela filosofia moderna, que assume que os seres humanos são sujeitos autônomos, cujos interesses e desejos são transparentes para eles mesmos e para os outros. O ator é visto imerso em um contexto social e em relação com os outros - por exemplo, uma comunidade de acadêmicos. Invocando "intenções", ativase uma cadeia de significantes, que são os vários autores e textos de uma certa tradição. Dessa forma, talvez a crítica mais significante das teorias apresentadas pelos dois autores relacione-se à ambição de construir "megassínteses teóricas" - o que é mais forte em Bourdieu.

É difícil identificar as possíveis aplicações e contribuições dos referenciais teóricos oferecidos pelos dois autores no âmbito da teoria organizacional. Principalmente, porque nenhum dos dois autores se propõe a contribuir para TO e os níveis de análise apresentam uma certa incompatibilidade. No entanto, no entender da autora deste trabalho, as teorias de Giddens e Bourdieu podem vir a encorajar a análise dinâmica e integrada dos níveis macro e micro-organizacionais, considerando o peso que atribuem à síntese da subjetividade - mais presente nas análises micro-organizacionais - e da objetividade - mais presente nas análises macro-organizacionais. Isso apresenta uma significativa contribuição ao campo, marcado por rígidas fronteiras estabelecidas entre os diversos níveis de análise.

Existem diversos trabalhos que fazem uso da abordagem de Bourdieu e Giddens. Em relação a Bourdieu, o conceito mais utilizado de sua análise tem sido o de campo - o que impressiona, considerando que se perde o foco da síntese e abre espaço para sérios questionamentos da validade de tais pesquisas, uma vez que, para o autor, habitus e campo são dialeticamente relacionados. É interessante observar que ao mesmo tempo em que o conceito de campo, trazido para a discussão pela teoria neoinstitucional, ganha espaço na literatura organizacional, autores brasileiros aplicam o conceito de campo oferecido por Bourdieu em pesquisas da área (Mincocky, 2001; Carvalho e Lopes, 2001; Leão, 2001).

Vale lembrar que Bourdieu realizou pesquisas importantes no decorrer de sua trajetória acadêmica. O autor construiu e consolidou sua teoria com base nas primeiras pesquisas antropológicas e as mais recentes pesquisas sociológicas. Sua aplicabilidade poderá se potencializar quando o conceito de habitus for também explorado, servindo como uma escala de intermediação entre os níveis macro e micro de análise organizacional.

$\mathrm{Na}$ literatura internacional, especialmente a de origem anglo-saxã, o impacto da teoria de estruturação 
de Giddens é maior. O autor fortaleceu o aspecto dinâmico da perspectiva organizacional e isso se reflete em pesquisas que tentam juntar conceitos de movimentos sociais com a teoria das redes, como na pesquisa desenvolvida por Stevenson e Greengberg (2000), que conclui que atores fracos, com uma posição desfavorável dentro da rede, também podem influenciar as políticas fazendo uso de estratégias diretas e sob condições políticas favoráveis ${ }^{11}$. Outro trabalho interessante no Brasil é de Junquilho (2001), que analisa as condutas gerenciais e suas raízes a partir do referencial da teoria de estruturação.

Novamente, não é objetivo de nenhum dos autores oferecer um referencial teórico que visa a ser aplicado na área organizacional. Seus objetos de análise são as práticas sociais. É importante reconhecer que parte da tradição de pesquisa de estudos organizacionais, caracterizada por uma certa dificuldade de enfocar seu objeto de estudo - a organização - a partir de uma visão unidisciplinar, busca a multidisciplinaridade, alimentando-se das contribuições de teorias psicológicas, sociológicas, econômicas e assim por diante, mas caindo na superficialidade. Talvez o maior desafio resida na identificação de conceitos que tais sínteses, significativas para o estudo das organizações, oferecem.

\section{Artigo recebido em 17/09/2002. Aprovado em 07/10/2002.}

\section{Notas}

A autora agradece a EBAPE/FGV pelo apoio institucional e os coordenadores do ENEO 2002, Professora Dra. Cristina Amélia P. Carvalho (PROPAD/UFPE) e Professor Dr. Marcelo Milano Falcão Vieira (EBAPE/ FGV e PROPAD/UFPE)

1. O autor usa o termo "individual" em um senso extenso, que inclui também os tomadores corporativos de decisão, como empresas e governos.

2. As duas correntes, originadas em Durkheim, enfatizam a prioridade da estrutura sobre a ação. A sociedade é vista como um ambiente inibidor, no qual atores se movimentam, e que se torna presente por meio de efeitos que pressionam e condicionam a conduta desses atores (Giddens, 1979, p. 51).

3. Elster também dedica uma parte de seu trabalho a essa análise.

4. Husserl também utiliza esse conceito em suas Meditações cartesianas, demonstrando, como Bourdieu, uma inspiração fenomenológica.

5. A dimensão praxiológica, no sentido de orientação social e de uma disposição afetiva.

6. "O aspecto relacional, sendo que, no mundo social, ser é estar situado e situar-se em um espaço diferenciado, ajustando-se a seus próprios possíveis e a eles somente" (Pinto, 2000, p. 39).

7. Revendo noções como interesse, estratégia ou capital, Bourdieu reconhece que a estratégia da prática pressupõe algo como um capital, mas um capital que, em certos gêneros, proíbe as formas explícitas de cálculo. Assim, a economia dos bens simbólicos pode caracterizar a dimensão econômica do habitus.

8. O aspecto categorial concerne ao trabalho lógico de ordenação do mundo a partir de um pequeno número de esquemas generalizáveis e transponíveis.

9. Assim como Giddens (1979), que faz uso extensivo do conceito de conhecimento prático, Bourdieu utiliza o conceito do conhecimento tácito, que está presente no habitus, quando analisa a sociedade kabila.

10. Usado aqui como sinônimo de pós-estruturalismo.

11. Ver também Klinj, Koppenjan e Termeer (1995), que conceituam redes como padrões, mais ou menos estáveis, de relações sociais entre atores mutuamente dependentes, estabelecidas em torno de problemas de políticas públicas ou agrupamentos de recursos, as quais são formadas, mantidas e modificadas por uma série de jogos. Enquanto o jogo seria uma série contínua e consecutiva de ações de diferentes atores, dirigido por regras formais e informais, estabelecidas em torno de questões ou decisões nas quais os atores têm interesse. O que se busca é uma gerência de redes que visa a melhorar a interação do jogo e os resultados, lidando, simultaneamente, com a rede (enquanto estrutura) e o jogo (enquanto interação).

\section{Bibliografia}

BARNARD, Chester I. As funções do executivo. São Paulo : Atlas, 1971.

BONAZZI, Giuseppe. Storia del pensiero organizzativo. Collana di sociologia. Milano : FrancoAgneli, 2000.

BOURDIEU, Pierre. Esqueisse d'une théorie de la pratique. Precede de trois études d'ethnologie kabyle. Geneve / Paris : Librairie Droz, 1972.

BOURDIEU, Pierre. Distinction. A social critique of the judgement of taste. Cambridge : Harward University Press, 1984.

BOURDIEU, Pierre. Questions de sociologie. Paris : Les Éditions de Minutis, 1984b.

CALÁS, Marta B., Smircich, Linda. Past pastmodernism? Reflections and tentative directions. The Academy of Management Review. Special topic forum on theory development: evaluation, reflections, and new directions. v. 24, n. 24 , Oct. 1999. 
CARVALHO, Cristina Amélia, LOPES, Fernando Dias. Convergência estrutural e processual entre teatros e museus no Rio Grande do Sul. In: ENCONTRO ANUAL DA ASSOCIAÇÃO NACIONAL DOS PROGRAMAS DE PÓS-GRADUAÇÃO EM ADMINISTRAÇÃO, 25oㅡ, Campinas. Anais... Campinas : ANPAD, 2001.

CASSELL, Philip. The Giddens reader. China : Macmillan Press, 1993.

CLEGG, Stewart R, HARDY, Cynthia, NORD, Walter R. (Orgs.) Handbook de estudos organizacionais. Modelos de análise e novas questões em estudos organizacionais. Vol. 1. Rio de Janeiro : Atlas, 1999.

DRUCKER, Peter. Administrando em tempos de grandes mudanças. São Paulo : Pioneira, 1995.

ELSTER, John. Nuts and bolts for the social sciences. Cambridge : Cambridge University Press, 1989

GIDDENS, Anthony. Central problems in social theory. Action, structure and contradiction in social analysis. Berkeley / Los Angeles : University of California Press, 1979

GIDDENS, Anthony. Social theory and modern sociology. Stanford : Stanford University Press, 1989

GRANOVETTER, Mark. Problems of explanation in economic sociology. In: NOHRIA, Nitin, ECCLES, Robert G. (Eds.). Networks and organizations: structure, form, and action. Boston : Harvard Business School Press, 1992.

JUNQUILHO, Gelson Silva. Condutas gerenciais e suas "raízes": uma proposta de análise à luz da teoria da estruturação. In: ENCONTRO ANUAL DA ASSOCIAÇÃO NACIONAL DOS PROGRAMAS DE PÓS-GRADUAÇÃO EM ADMINISTRAÇÃO, 25ํㅡㄹ Campinas. Anais... Campinas : ANPAD, 2001

KLIJN, Erik-Hans, KOPPENJAN, Joop, TERMEER, Katrien. Managing networks in the public sector: a theoretical study of management strategies in policy networks. Public Administration, v. 73, p. 437-54, Autumn 1995.
LEÃO, Fernando Pontual de Souza J. Formação e estruturação de campos organizacionais: um modelo para a análise do campo cultural. In: ENCONTRO ANUAL DA ASSOCIAÇÃO NACIONAL DOS PROGRAMAS DE PÓS-GRADUAÇÃO EM ADMINISTRAÇÃO, 25ํㅡㄹ Campinas. Anais... Campinas : ANPAD, 2001

LINBDLOM, Charles Edward. O processo de decisão política. Brasília : Ed. da UnB, 1981.

MISOCZKY, Maria Ceci A. Campo de poder e ação em Bourdieu: implicações de seu uso em estudos organizacionais. In: ENCONTRO ANUAL DA ASSOCIAC̄̃̃O NACIONAL DOS PROGRAMAS DE PÓS-GRADUAČ̃̃O EM ADMINISTRAÇÃO, 25으, Campinas. Anais... Campinas : ANPAD, 2001.

PINTO, Louis. Pierre Bourdieu e a teoria do mundo social. Rio de Janeiro : Ed. da FGV. 2000

SIMON, Herbert A. Administrative behavior: a study of decision-making processes in administrative organization. $2^{\mathrm{a}} \mathrm{ed}$. New York : Macmillan, 1961.

STEVENSON, William. B., GREENBERG, Danna. Agency and social networks: strategies of action in a social structure of positions, opposition and opportunity. Administrative Science Quarterly, n. 45, p. 651-78, 2000

TAYLOR, Frederick Winslow. Princípios de administração científica. $7^{\mathrm{a}} \mathrm{ed}$. São Paulo : Atlas, 1970.

WAHRLICH, Beatriz M. de Souza. Uma análise das teorias de organização. 5a ed. Rio de Janeiro : Ed. da FGV, 1986.

WEBER, Max. Economia y sociedad. México, D.F. : Fondo de Cultura Economica, 1944.

WEBER, Max. A ética protestante e o espirito do capitalismo. 15a ed. São Paulo: Biblioteca Pioneira de Ciências Sociais, 2000.

WEICK, Karl. A psicologia social da organização. São Paulo : E. Blucher / Edusp, 1973.

\section{Alketa Peci}

Pesquisadora do Centro de Acompanhamento Acadêmico e Pesquisa, EBAPE/FGV. Doutoranda em Administração

pela EBAPE/FGV e Pesquisadora Visitante da George Washington University . Interesses de pesquisa em

Perspectivas Paradigmáticas e Pesquisa Organizacional, Teoria Organizacional, e Regulação de Serviços Públicos.

E-mail: alketa@fgv.br

Endereço: EBAPE/FGV - Praia de Botafogo, 190, sala 513.1 - Rio de Janeiro, RJ. CEP 22253-900 